\title{
The Influence of Entrepreneurial Learning Environment and Intrinsic Learners' Need on Entrepreneurship Education
}

\author{
Mahabub Musa Garba, Shamsu Lawan Abubakar* \\ Department of Business Administration, Faculty of Social and Management Sciences, Northwest University, Kano, Nigeria \\ Email: mmgarba@gmail.com, *shamsulawan46@gmail.com
}

How to cite this paper: Garba, M.M. and Abubakar, S.L. (2019) The Influence of Entrepreneurial Learning Environment and Intrinsic Learners' Need on Entrepreneurship Education. Open Journal of Business and Management, 7, 1244-1261.

https://doi.org/10.4236/ojbm.2019.73087

Received: May 15, 2019

Accepted: July 9, 2019

Published: July 12, 2019

Copyright ( 2019 by author(s) and Scientific Research Publishing Inc. This work is licensed under the Creative Commons Attribution International License (CC BY 4.0).

http://creativecommons.org/licenses/by/4.0/

\begin{abstract}
For human and economic development to be achieved certain factors need to come into play, one of being the proliferation of entrepreneurship as a carrier choice. The aim of this study is to examine the influence of Entrepreneurial Learning Environment (ELE), Intrinsic Learners' Need (ILN) on Entrepreneurial Learning Outcome (ELO) and the mediating relationship of Entrepreneurial Motivation (EM) on the relationship of ELE and ILN on ELO. The population of the study was drawn from three universities (Yusuf MaitamaSule University, Kano, Kano University of Science and Technology and Bayero Univeristy, Kano). A total of 14,446 students formed the population of the study; 345 students constitute the sample size which was drawn using priory sample size calculator and stratified sampling technique was used in selecting the respondents. The data were analysed using structural equation modelling. Findings of the study revealed that ELE is the most important factors that influence students' ELO and ILN and EM have insignificant influence toward ELO. Therefore, the study recommends that practicing entrepreneurs need to be involved in the teaching of entrepreneurship education.
\end{abstract}

\section{Keywords}

Entrepreneurial Learning Environment, Intrinsic Learners' Need, Entrepreneurial Learning Outcome of Entrepreneurship Education

\section{Introduction}

The aim of an entrepreneurship education programme is to prepare and train individuals to be self-employed and self-determining individuals. It is about making one to develop entrepreneurial propensity and to encourage future entrepreneurs to venture into business [1]. Many studies have been conducted in 
the area of entrepreneurship education among which includes: factors motivating one's decision to opt into entrepreneurship as a career, factors that hinders one's desire to choose entrepreneurship as a career, personalities factors that have effect on entrepreneurship, theoretical frameworks that influence one's tendency to become an entrepreneur and the importance of entrepreneurship education towards job stimulations [2]-[9]. There are a plethora of researches which examined the antecedents that influenced one's intention and attitude to become an entrepreneur. Therefore, studying the environment that may lead to the effective entrepreneurial learning outcomes is imperative, because the components of entrepreneurial learning outcomes can lead to an entrepreneurial society.

Entrepreneurship is generally believed to be the engine of human progress and solution for social and economic problems. Social vices such poverty, unemployment, crimes and many more could be curtailed through proliferation of entrepreneurship. It is established based on empirical evidences that economic growth is a necessary condition for poverty reduction and entrepreneurship is what boosts economic growth [10]. According to Garba, Kabir, and Nalado [7] entrepreneurship is being recognised as one of the necessary conditions for economic development. Furthermore, Volkman, Wilson, Marlotti and Rabuzzi [10] stated that entrepreneurship is the bedrock of economic development, structural change, job creation and also a way to tackle the challenges of poverty. Entrepreneurship signifies individual's ability to turn ideas into action. It comprises of creativity, innovation and taking calculated risk, as well as the ability to plan and manage projects in order to achieve certain goals. This supports everyone in day-to-day life at home and in society; makes employees more aware of the context of their work and better prepared to seize opportunities, and provides a foundation for entrepreneurs, establishing a social or commercial activity [11]. From the foregoing, the sustenance of better society is largely revolved around entrepreneurship.

\section{Problem Statement}

Formal education in Nigeria prepares students and graduates to be job seekers rather than job creators. In the 1960s to early 80s, the reality was that as soon as students graduate or obtain a degree an offer of employment awaited them. Therefore, graduate employment was never an issue then. But in the mid-80s, after the introduction of the Structural Adjustment Programme (SAP), graduate employment became a bedeviling issue. Arogundade [12] reported that in the middle of 80 s, the Nigerian economy fell into the state of economic downfall, which led to a large-scale layoff of workers. This further aggravated the youth and graduate unemployment in Nigeria. However, the level of graduate unemployment in Nigeria has kept on skyrocketing, despite the fact that the country is endowed with human and natural resources. Every year Nigerian tertiary institutions keep on producing graduates without concomitant provision of jobs that can cater for them. Meanwhile, about $80 \%$ of the Nigerian graduates find it dif- 
ficult to get employment every year [13]. Thus, this has stimulated the Nigerian University, Commission (NUC) to introduce Entrepreneurship Education Programme across all universities in Nigeria in order to create entrepreneurial culture, sprit and also to enable graduates to appreciate the culture of job creating rather than job seeking. The assumption is that EEP will influence students' inclinations and propensity towards entrepreneurship and hence students' career choice. Studies conducted by Aja-Okorie and Adali [14] as well as Adebayo and Kolawole [15] have established that entrepreneurship education has a positive effect on entrepreneurial intentions of university students in Nigeria. However, Ayodele [16] asserted that university students in Nigeria are not able to translate their intentions into the achievement of entrepreneurial goals and aspirations at graduation. He also stated that, the success of any knowledge or skill development initiative is largely determined by the participants' learning orientation. According to Mohd. and Syde [17] inappropriate teaching method is a factor capable of frustrating students' action into entrepreneurial one upon graduation. According to Ojeifo [18] EEP has no significant impact on students' entrepreneurial skills and that EEP is negatively related to entrepreneurial intention. Considering the aforementioned problems, this study seeks to examine the influence of ELE, and ILN, on ELO among university graduates in three universities in Kano-Nigeria and to examine the mediating effect of EM on the existing relationship.

\section{Theoretical Framework and Literature Review}

From the various researches, it has been established that entrepreneurial intention, skills and attitude are among the entrepreneurial outcomes. According to Lee, Chang and Lim [19] effective entrepreneurship education and a good concept of venture creation will enhance entrepreneurship and strengthened entrepreneurship intention and desire for venture creation. In a study conducted by OECD [11] it is argued that an entrepreneurial skill is one of outcomes to be attained through EEP. Furthermore, Valerio, Parton and Robb [20] affirmed that EEP primarily aims to promote entrepreneurial skills and attitude. However, most researchers have shown that an increase in individual self-reported intentions to begin a business is largely determined by the exposure to certain types of EEP. Meanwhile, several studies have indicated that EEP creates self-sufficient, motivated and enterprising individuals who leave the education system with skills to start their own business or abilities to create innovation in established organizations [21]. Thus, details of ELO can be briefly described.

Entrepreneurial Intention (EI), according Watson, Hogarth-Scott and Wilson [22] intention for venture creation is one of the critical factors for successful entrepreneurship. Thompson [23] defined EI as self-acknowledged conviction by a person that intends to set up a new business venture and consciously plans to do so at some point in the future. According to Delmar and Davidsson [24] EI is the foundation of new venture creation. Therefore, EI is a prerequisite toward entrepreneurial action. Oosterbeek, Van Praag and Ijsselstein [25] established that 
EEP has no significant impact on students' entrepreneurial skills and also EEP is negatively related to entrepreneurial intention. Therefore, other factors may be the determining factors toward ELO, especially in the area of entrepreneurial skills and intentions.

Entrepreneurial attitude (EA), according to the Advance Learner Dictionary (online version) is a complex mental state involving beliefs, feelings, values and dispositions to act in certain ways. In some literature, attitude is largely linked to behaviour, because, it is through attitude behaviour is being developed. Even though distinction is usually made between the two, but attitude is behaviour that is dynamic in nature and certain precipitating events alter it. According to Theory of Planed Behaviour, certain attitudes determine behaviours [26]. Therefore, in the area of entrepreneurship; entrepreneurship education, entrepreneurship experience and other exogenous factors may change an entrepreneurial attitude of students [7]. Attitude is among the factors that encourage and motivate a person's decision to become an entrepreneur [27]. Kolvereid [28] found attitude towards entrepreneurship, favourable social norms and strong entrepreneurial self-efficacy positively influence individuals and student's intention to become entrepreneurs.

Entrepreneurial skills (ES) are the skills needed by a person to succeed in business. They are basic skills that enable one to start, develop, finance and succeed in home enterprise [29]. According to Oosterbeek, Van Praag and Ijsselstein [25], entrepreneurial skills can be measured using three important elements: entrepreneurs' market awareness, creativity and flexibility. However, skills can be taught and learned and can be improved through entrepreneurial education.

In a study conducted by Cho [30] it is revealed that entrepreneurship education promotes the intention of venture creation, because entrepreneurship-related knowledge and skills stimulate an individual's motivation to create a new venture. In another study by Han and Lee [31] it is argued that EEP increase confidence for an individual to start a business venture, while Timmons [32] stated that if an individual has an appropriate knowledge of entrepreneurship and intention for venture creation they can significantly produce a successful venture. Thus, EEP increases knowledge about venture creation. Lee, Chang and Lim [19] examined the impact of EE on entrepreneurial intention of university students of two different countries US and Korea. The findings show that the effect of EEP toward improvement EI is slightly significant between two groups of students that took EEP courses and those that do not take in US Universities and strongly significant among the two groups of students in Korean universities. The paper showed that both in US and Korean universities, EEP play a significant role toward entrepreneurial intention and confidence but entrepreneurial culture in the US shows that even if you do not attend EEP courses students have inclination toward entrepreneurship. Therefore, even though EE influences students' EI but entrepreneurial culture has a significant impact on EI among US students. In the study of Wilson, Kickul and Marlino [33] EE increases a student's interest in entrepreneurship as a career, while Souitaris, Zerbinati and Al-Laham [34] ob- 
served that entrepreneurship programs considerably increase students' subjective norms and intentions toward entrepreneurship by motivating them to choose entrepreneurial careers. Turke and Sulcek [35] asserted that adequate education may promote the EI of a person. Neneh [6] in his study in Cameroonian universities found that EEP is not factors that strongly influence students' EI but push factors such as unemployment, poverty and job insecurity are the strong factors that influence their entrepreneurial intention. Thus, entrepreneurial attitudes and overall intentions to become future entrepreneurs can be triggered from exposure to an EEP. Other studies are of the view that EEP alone cannot trigger ELO, but other factors such as entrepreneurial environment, learners' inclination toward entrepreneurship, entrepreneurial motivations and other related factors may be effective variables that can influence ELO.

Lucky and Auwalu [36] examined the relationship between entrepreneurial environments on entrepreneurial intention but the study has not integrated the ELE as a construct of entrepreneurial environment. One of the recent studies that examined ELE is a study conducted by [37] which studied the relationship between ELE and EI of students of Jakarta, Indonesia, the study affirmed that students' entrepreneurial intentions are affected directly and positively by the learning environment. The study further showed that ELE has positive impact on entrepreneurial attitude but the study remained silent on the relationship between ELE and students' entrepreneurial skills.

According to OECD [11] ELE can be understood from the perspective of entrepreneurial environmental elements such as physical and mental rooms, teachers' professionally related perception and attitude and collaboration with the surrounding world. Physical room refers to things like class room, school premises, businesses, the internet etc. Mental room refers to the content, methods, approaches and contexts utilised by the teacher. This includes the type of assignments and whether they allow for and encourage students' own initiatives, creativity and responsibility. The teachers' perceptions of and attitudes towards knowledge, theories of learning, learning styles and the students' resourcefulness in their own learning process are also important in shaping a learning environment. Teachers are aware of how their professionally related perceptions and attitudes shape the learning environment of their students. The way and manner teachers teach may have a significant influence on learning environment. While, the paper has highlighted the constituencies of ELE but has not examine how ELE influence ELO.

According to Neneh [6] what makes students opt for entrepreneurship or to have an entrepreneurial intention was largely determined by push factors. The scholar further asserted that EEP, gender and family background have no significant influence toward one's desire to select entrepreneurship as a career upon graduation. Thus, factors like unemployment, poverty and job security are the reasons why graduate students in Cameroon chose entrepreneurship as career path. Oosterbeek [25] further stated that EEP has no significant influence on the 
EI, EA and ES. Ayodele [16] asserted that University students in Nigeria are not able to translate their intentions into the achievement of entrepreneurial goals and aspirations upon graduation. Thus, other factors such as individual orientation towards learning need to be examined to see how they affect ELO. According to Bany and Johnson [38] classified individuals need to learning into intrinsic and extrinsic. They further stated that intrinsic need involves satisfying the needs for the purpose of primary objectives, and this type of learners' need is self-motivated needs. Extrinsic learners' need is a need to satisfy objectives or performing activity because it leads to some external rewards. According to Simola [39] intrinsic needs refer to a person's interest to do something because he/she enjoys doing it, while extrinsic refers to a person's desire to do something because of external rewards such as money and awards etc. In the Theory of Entrepreneurial Event developed by Shapero and Sokol [40] creation of entrepreneurial organisation is largely influence by contextual factors, one of which is perceived desirability. External factors may not only be a reason for one to become an entrepreneur but one's desire can influence his/her decision to become an entrepreneur [40]. Thus, perceived desirability and intrinsic learners' need may be a determining factor in influencing one's decision to learn about entrepreneurship.

Entrepreneurial motivation (EM) is one of the renowned variables that are widely used in entrepreneurship education research. They are broadly classified into push and pull factors [41]. Based on the plethora of research, push factors are termed as negative factors because they are usually associated with displeasing situations such as poverty, unemployment and other related factors, pull factors are related to issues that are interested to individuals. According to Eijdenberg and Masurel [41] DeMartino and Barbato [42] pull factors are factors that are positive to individuals. They include working autonomously, being one's own boss, job security, excessive wealth creation, financial autonomy, power and control in decision making etc. Despite the factors are classified into pull and push, but the most interesting factors that are need to be possessed by entrepreneurs or potential entrepreneurs are pull factors. In this study, pull factors will be used to examine their relationship with ELO.

Based on the review of literature, the following framework and hypotheses were developed (Figure 1).

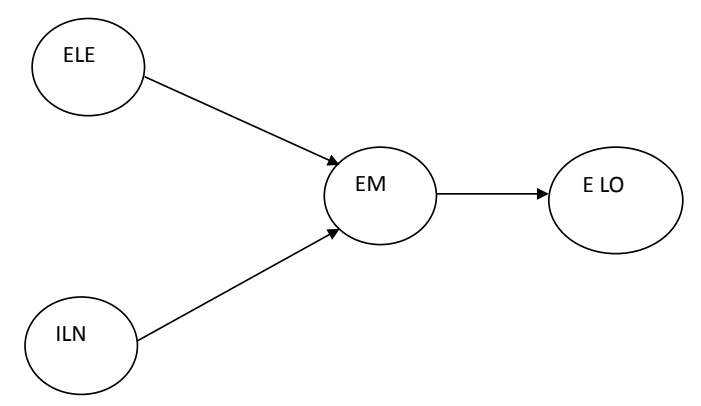

Figure 1. Study framework. 
1) There is significant relationship between ELE and ELO;

2) There is significant mediating relationship of EM on ELE and ELO;

3) There is significant relationship between ILN and ELO;

4) There is significant mediating relationship between of EM on ILN and ELO;

5) There is significant relationship between EM and ELO.

\section{Methodology}

\subsection{Research Design and Population of the Study}

The study used descriptive survey design to examine the influence of entrepreneurial learning environment (ELE), intrinsic learners need (ILN) on entrepreneurial learning outcome (ELO) and the effect of entrepreneurial motivation (EM) toward mediating the relationship of the two independent variables and the dependent variable of the study. In order to achieve the objectives, the study, university students were considered to form the population of the study, specifically the students of three varsities that are in Kano state of Nigeria. Yusuf Maitama Sule University, Kano (YUMSUK), Kano University of Science and Technology (KUST) and Bayero University, Kano (BUK). Students that have undertook entrepreneurship education programme for 2017/2018 academic session formed the population of the study. According to figure received from the three different universities, BUK has 6600 students, KUST has 4446 students and YUMSUK has 3400 students making a total of 14446.

\subsection{Sample Size and Sampling Technique}

To determine the sample size a Priori sample size calculator was used, a sample of 345 students was arrived at, out of which 81 students are from YUMSUK, 106 students from KUST and 158 students from BUK respectively. To establish clear sample size a stratified simple random sampling technique was employed. Each of the three universities was considered as a strata and all students have an equal chance of been selected to form the sample size of the study.

\subsection{Validity and Reliability of the Instrument}

The study used questionnaire as an instrument for data collection for the research, the questionnaire was developed on the basis of the variables of the study. ELO was measured based on nine items, ELE was also measured using seven items, ILN was measure using five items and EM was measured using six items. Content validity of the instrument was conducted prior to administering the questionnaire for pilot study. Thus, the result of internal reliability analysis is presented in Table 1.

Table 1 presents information with respect to the internal reliability of the instrument; it shows that all the constructs have reached the minimum threshold of 0.70 as recommended. Therefore, in Table 1 ELO has Cronbach Alpha value 0.744, ELE has Cronbach Alpha value of 0.711, ILN has Cronbach Alpha value of 0.715 and EM has Cronbach Alpha value of 0.880 . This indicates that all the variables are reliable and can be used for further data collection. 
Table 1. Result of internal reliability.

\begin{tabular}{ccccc}
\hline \multicolumn{5}{c}{ Result of Internal Reliability } \\
\hline 1 & Construct & Items & No of respondents & Cronbach Alpha \\
\hline 2 & ELO & 9 & 100 & 0.744 \\
3 & ELE & 7 & 100 & 0.711 \\
4 & ILN & 5 & 100 & 0.715 \\
\hline
\end{tabular}

Source: Pilot Data 2018.

\section{Analyses of the Research Data}

The method employed for the analyses of the research data was structural equation modeling (SEM) through the use of AMOS software version 23. Therefore, to do that a series of activities need to be undertaken such as measurement model and analyses of the hypotheses.

\subsection{Response Rate}

This section depicts information in respect of the response rate, Table 2 provides hint in respect to questionnaire administered and returned.

Table 2 shows that three hundred and forty-five questionnaires were administered and the same figure was returned and three hundred and forty-three questionnaires were reported valid and only two of the questionnaires were invalid. Based on the information in Table 2 three hundred and forty-three valid questionnaires would be used in the subsequent analysis of the data which is equivalent to 99 percent of the total administered questionnaires.

\subsection{Demography of the Respondents}

Basically, the data collected has demographic information of the respondents. Personal profile of the respondents was reported and presented in Table 3.

Table 3 provides information regarding demography of the respondents. The table started by gender of the respondents. The Respondents are categorized into male and female. The male are 190 respondents which are equivalent to $55.4 \%$ and 153 female respondents which are equivalent to $44.6 \%$. Thus, the data shows that majority of the respondents are male and this signifies that there were more female than male in term of EEP course.

Table 3 also presents information regarding to ages of the respondents, in the table it shows that there are different categories of ages among the respondents. But it shows that majority of the respondents are below 30 years. This signifies that majority of the students that took EEP course are young persons.

On the part of the marital status, the table also presents different categories of the respondents. Table 3 shows that majority of respondents are single.

Meanwhile, the table also presents information regarding the universities of the respondents. However, majority of the respondents are from BUK. 
Table 2. Response rate.

\begin{tabular}{ccc}
\hline & Response Rate & \\
\hline Description & Frequency & Percentage \\
\hline $\begin{array}{c}\text { Administered } \\
\text { Questionnaire } \\
\text { Returned } \\
\text { Questionnaire } \\
\text { Valid questionnaire }\end{array}$ & 345 & 100 \\
\hline
\end{tabular}

Source: Survey Data (2018).

Table 3. Bio data of the respondents.

\begin{tabular}{|c|c|c|}
\hline \multicolumn{3}{|c|}{ Bio Data of the Respondents } \\
\hline $\begin{array}{c}\text { Characteristics of the } \\
\text { Respondents }\end{array}$ & Frequency & Percentage \\
\hline \multicolumn{3}{|l|}{ Gender } \\
\hline Male & 190 & 55.4 \\
\hline Female & 153 & 44.6 \\
\hline Total & 343 & 100 \\
\hline \multicolumn{3}{|l|}{ Age } \\
\hline Below 30 year & 274 & 79.9 \\
\hline $31-40$ year & 61 & 17.8 \\
\hline $41-50$ & 08 & 2.3 \\
\hline 51 and above & 00 & 00 \\
\hline Total & 343 & 100 \\
\hline \multicolumn{3}{|l|}{ Marital Status } \\
\hline Single & 261 & 76.1 \\
\hline Married & 76 & 22.2 \\
\hline Widow & 00 & 00 \\
\hline Divorced & 06 & 1.7 \\
\hline Total & 343 & 100 \\
\hline \multicolumn{3}{|l|}{ University } \\
\hline YUMSUK & 81 & 23.6 \\
\hline KUST & 105 & 30.6 \\
\hline BUK & 157 & 45.8 \\
\hline Total & 343 & 100 \\
\hline \multicolumn{3}{|l|}{ Offered EPP } \\
\hline YES & 343 & 100 \\
\hline NO & 00 & 00 \\
\hline Total & 343 & 100 \\
\hline \multicolumn{3}{|l|}{ Level Offered } \\
\hline 100 & 00 & 00 \\
\hline 200 & 00 & 00 \\
\hline 300 & 107 & 31.2 \\
\hline 400 & 00 & 00 \\
\hline 300 and 400 & 236 & 68.8 \\
\hline Total & 343 & 100 \\
\hline
\end{tabular}

Source: Survey Data (2018). 
Table 3 also shows that in term of offering EEP, all the respondents have undertaken EEP in their universities. None of the respondents reported that he has not been taken EEP as a course.

Lastly, Table 3 shows the level at which EEP is being offered in those universities, it only shows EEP is offered in level 300 and level $300 \& 400$ in most cases. Therefore, Table 3 it shows that majority of the respondents offered EEP in level $300 \& 400$.

\subsection{Confirmatory Factor Analysis and Measurement Model}

Figure 2 shows that the model is not suitable to test the hypotheses because some the fitness indexes do not meet up with requirement of the analysis. From the fitness indexes it can be seen that P-Value, RMSEA and ChiSq/df are all okay because there are within the required threshold point, while GFI, CFI, TLI and NFI are below the required threshold point. In view of that further measurement of the model need to be done by deleting items that are below 0.6 or correlating items that have value from 15 and above.

Figure 3 shows that all the items in the fitness indexes have reached the required threshold point. Thus, at this stage structural equation modeling needs to be conducted in order to test hypotheses of the study.

\subsection{Hypotheses Testing Using Structural Equation Modelling}

Hypotheses are the principal elements in quantitative research; they are assumptions to be proved or disprove [43]. They are tentative statement which predicts what to expect from empirical data and there are derive from previous work and theory. This section will test the hypotheses of the study using figures and tables (Figure 4).

1) There is significant relationship between ELE and ELO

This Hypothesis 1 in Table 4 has examined the relationship between ELE and ELO. From the analysis, the result revealed that the proposed relationship indicates that the relationship was statistically not significant $(\beta=0.460, \mathrm{P}>0.005)$. The result shows that when ELE goes up by 1 , ELO goes up by 0.46 . The result revealed that ELE is positively related to ELO but not significantly related. This indicates that the hypothesis is rejected (Figure 5).

2) There is significant mediating relationship of EM on ELE and ELO

This Hypothesis 2 in Table 5 examined the mediating relationship of EM on ELE and ELO. From the analysis, the result revealed that the proposed relationship indicates that the relationship was statistically not significant ( $\beta=$ $0.392, \mathrm{P}>0.005$ ). The result shows that when ELE goes up by 1 , ELO goes up by 0.39 where EM is involved. The result revealed that there is partial mediation of EM in the relationship of ELE to ELO. The hypothesis is rejected (Figure 6).

3) There is significant relationship between ILN and ELO

This Hypothesis 3 in Table 6 has examined the relationship between ILN and 
Table 4. ELE \& ELO regression weights and its significance.

\begin{tabular}{cccccc}
\hline \multicolumn{5}{c}{ ELE \& ELO regression weights and its significance } \\
\hline $\begin{array}{c}\text { Hypothesized } \\
\text { Path }\end{array}$ & Estimate & S.E. & CR & P Value & Result \\
ELE-----> ELO & 0.460 & 0.250 & 1.842 & 0.065 & $\begin{array}{c}\text { Not } \\
\text { significant }\end{array}$ \\
\hline
\end{tabular}

Table 5. Mediating relationship of ELE \& ELO regression weights and its significance.

Mediating Relationship of ELE \& ELO Regression Weights and its significance

$\begin{aligned} & \text { Hypothesized } \\ & \text { Path }\end{aligned}$
ELE---->ELO Estimate

Figure 2. None achievable fitness indexes.

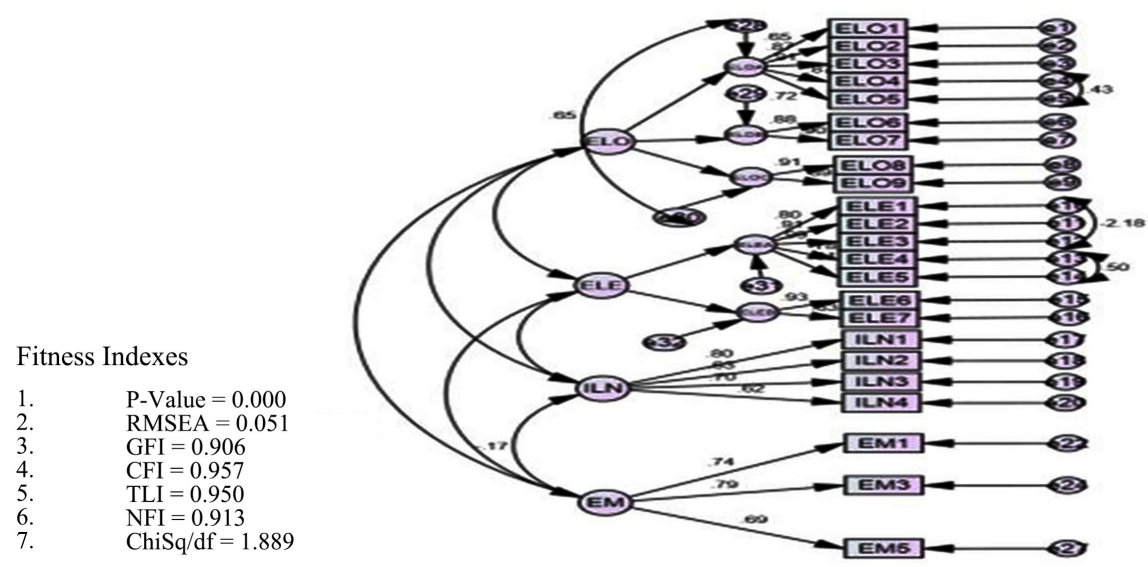

Figure 3. Achieved fitness indexes. 


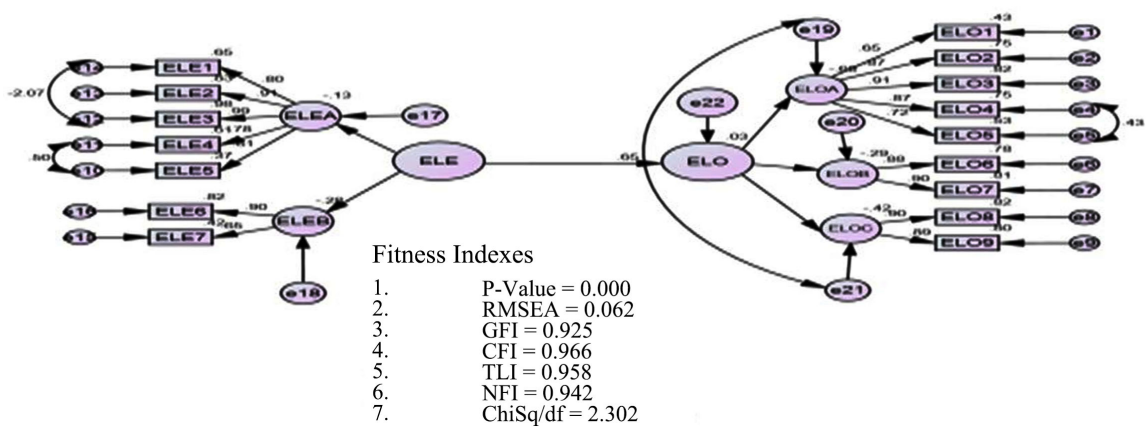

Figure 4. ELE \& ELO relationship.

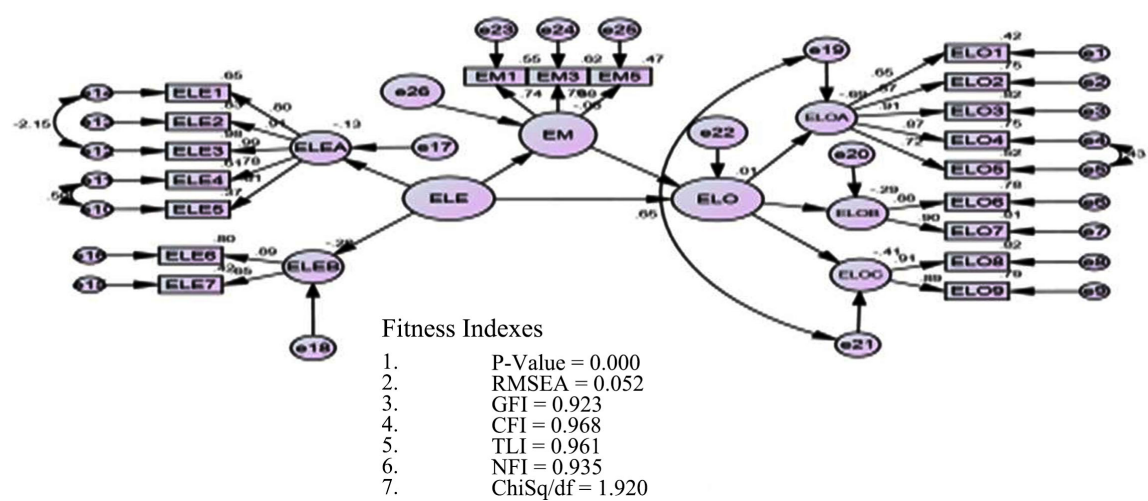

Figure 5. The mediating relationship of EM on ELE and ELO.

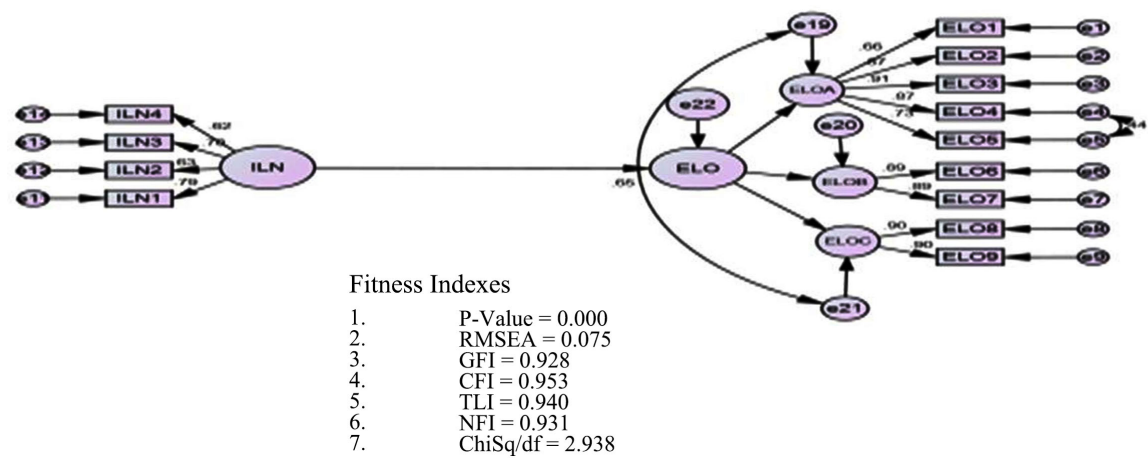

Figure 6. ILN \& ELO relationship.

ELO. From the analysis, the result revealed that the proposed relationship indicates that the relationship was statistically not significant $(\beta=0.014, \mathrm{P}>0.005)$. The result shows that when ILN goes up by 1 , ELO goes up by 0.014 . The result revealed that there is very little positive relationship between ILN and ELO. Indeed, ILN does not influence students' ELO. This indicates that the hypothesis is rejected (Figure 7).

4) There is significant mediating relationship between of EM on ILN and ELO

This Hypothesis 4 in Table 7 has examined the mediating relationship of EM on ILN and ELO. From the analysis, the result revealed that the proposed relationship indicates that the relationship was statistically not significant $(\beta=0.019$, $\mathrm{P}>0.005)$. The result shows that when ILN goes up by 1 , ELO goes up by 0.019 
where EM is involved. The result revealed that there is no mediation of EM in the relationship of ILN to ELO. The hypothesis is rejected (Figure 8).

5) There is significant relationship between EM and ELO

This Hypothesis 5 in Table 8 has examined the direct relationship of EM on ELO. From the analysis, the result revealed that the proposed relationship indicates that the relationship was statistically not significant $(\beta=0.037, \mathrm{P}>0.005)$. The result shows that when EM goes up by 1 , ELO goes up by 0.037 . The result revealed that there is little positive relationship between EM and ELO. The hypothesis is rejected.

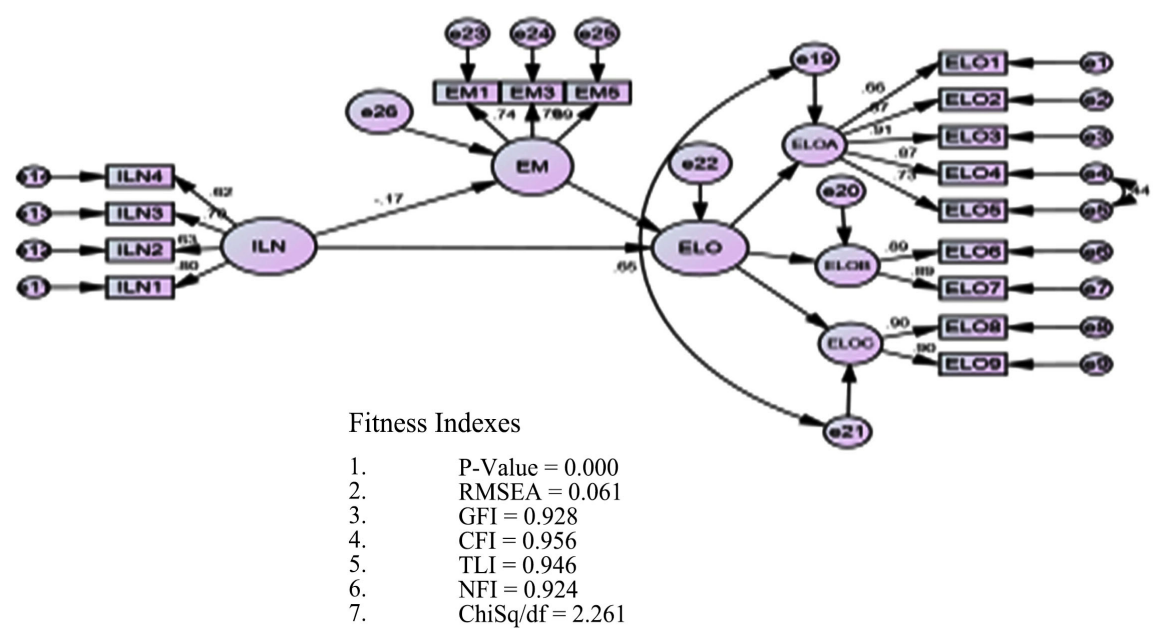

Figure 7. Mediating relationship of EM on ILN and ELO.

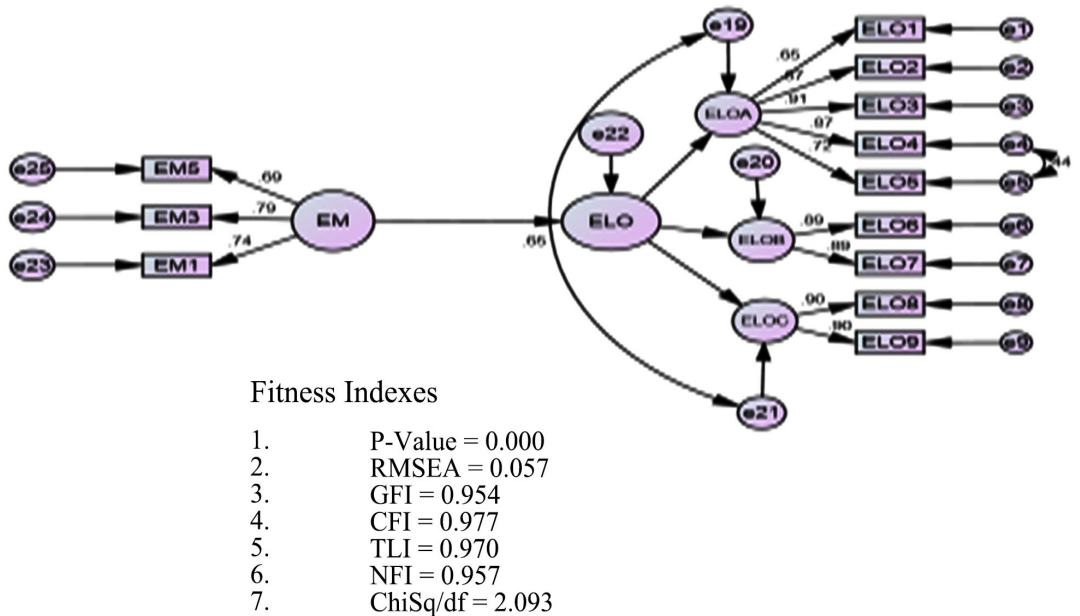

Figure 8. EM \& ELO relationship.

Table 6. Relationship of ILN \& ELO regression weights and its significance.

\begin{tabular}{lccccc}
\hline \multicolumn{5}{c}{ Relationship of ILN \& ELO Regression Weights and its significance } \\
\hline $\begin{array}{lccccc}\text { Hypothesized Path } \\
\text { ILN------>ELO }\end{array}$ & Estimate & S.E. & CR & P Value & Result \\
& 0.014 & 0.014 & 0.612 & 0.541 & Not significant \\
\hline
\end{tabular}


Table 7. Mediating relationship of EM on ILN and ELO.

\begin{tabular}{cccccc}
\hline \multicolumn{5}{c}{ Mediating relationship of EM on ILN and ELO } \\
\hline Hypothesized Path & Estimate & S.E. & CR & P Value & Result \\
ILN------>ELO & 0.019 & 0.023 & 0.829 & 0.407 & Not significant \\
\hline
\end{tabular}

Table 8. Relationship of EM \& ELO regression weights and its significance.

\begin{tabular}{cccccc}
\hline \multicolumn{5}{c}{ Relationship of EM \& ELO Regression Weights and its significance } \\
\hline $\begin{array}{c}\text { Hypothesized Path } \\
\text { EM------>ELO }\end{array}$ & Estimate & S.E. & CR & P Value & Result \\
& 0.037 & 0.025 & 1.455 & 0.146 & Not significant \\
\hline
\end{tabular}

\subsection{Discussion of the Results}

In the analyses of the hypotheses, all the independent variables (ELE, ILN and EM) are positively correlated to the dependent variable (ELO). But the results show that ELE has the highest positive correlation with ELO. In this study, it can be deduced that once there is ELE the better for the students to pursue entrepreneurship as a carrier. However, the impact of ILN and EM toward entrepreneurial pursue is very meagre and insignificant. Therefore, this study has a nexus with the study of Soptono and Purwana [33] which found that Students entrepreneurial intentions are affected directly and positively by the learning environment. Meanwhile, this study also affirmed the finding of Neneh [28] which revealed that push factors such as unemployment, poverty and job insecurity are the determinants of students' entrepreneurial intention upon graduation. ILN factors such as self-motivated factors, and EM factors such as being my own boss, like to be recognised and respected, employing other people are not the triggers of entrepreneurship among students. This contradict the findings of [17] [18].

\section{Conclusions and Recommendations}

The study has examined the influence of entrepreneurship education ecosystem toward entrepreneurial learning outcome. In other words, the study investigated the influence of ELE, ILN and EM in the predictions of ELO. Thus, based on the analyses and discussions of the study the followings findings and recommendations are established.

ELE is the most important factor that influences students' ELO, even though they are not significantly related; however improvement needs to be made especially involving practicing entrepreneurs in teaching of EEP and establishment of Business Incubation Centres so as to facilitate positive entrepreneurial learning.

ILN shows that the influence of it in students' ELO is almost nothing; therefore, it can be deduced that most of the students have no interest about entrepreneurship as a carrier upon graduation and they do EEP as perquisite upon which without passing the course you cannot graduate from the university. In 
this case the teachers need to do more in making students appreciate the culture job creations.

EM as a mediator, in the findings shows that there is partial mediating relationship between ELE and ELO where EM is involved and no mediation relationship exist between ILN and ELO. This shows that there is positive a correlation between ELE and EM while there is negative correlation between ILN and EM. This further demonstrates that ELE has much more impact toward ELO than any other variable in view of that entrepreneurship education needs to be sustained if the learning environment can be improved especially in the universities.

It is imperative to know that this study has regressed the relationship between ELE, ILN, EM and ELO using university students in Kano, Nigeria. Future study needs to consider the moderating effect of other variables such as students' family background, peer group and mentoring in examining the existing relationship. Meanwhile, in this study attention was dully given to three universities that are in Kano; therefore, more universities need to be integrated especially those in Northwest of Nigeria because they have similar futures.

\section{Acknowledgements}

The authors would like to thank Ismaila Garba Bala and Abubakar Mukhtar Yakasai for their support, comments and suggestions.

\section{Funding}

This project was funded by Tertiary Education Trust Fund (TETFUND).

\section{Conflicts of Interest}

Entrepreneurial education was introduced into the undergraduate curriculum of Nigerian Universities in 2006. The objective was to furnish students with the necessary skills for entrepreneurial success upon graduation. The aim of the programme was to reduce unemployment in the country, particularly graduate unemployment. This paper examines the influence of the entrepreneurial learning environment and learners' self-motivation on the outcome of the learning. Furthermore, the paper analyses the connection between entrepreneurial motivation on the association of entrepreneurial learning environment and on the learners' self-motivation on entrepreneurial learning outcome.

We found that the entrepreneurial learning environment is the most important factor influencing the students' learning outcome. Learners' self-motivation and entrepreneurial motivation have little influence toward entrepreneurial learning outcome.

The authors declare no conflicts of interest regarding the publication of this paper.

\section{References}

[1] Ahmad, S.Z., Abu Bakar, A. and Ahmad, N. (2018) An Evaluation of Teaching Me- 
thods of Entrepreneurship in Hospitality and Tourism Programs. The International Journal of Management Education, 16, 14-25. https://doi.org/10.1016/j.ijme.2017.11.002

[2] Ismail, A. (2015) The Entrepreneurial Attitude and Intentions of Newly Enrolled University Students-Issues and Policy Implications. Journal of Research in Business, Economics and Management, 4, 426-436.

[3] Jaquiline, A. (2013) Social Influence and Occupational Knowledge as Predictors of Career Choice Intentions among Undergraduate Students in Tanzania. International Journal of Learning \& Development, 3, 185-193.

https://doi.org/10.5296/ijld.v3i3.3990

[4] Agbim, K.C., Godday O.O. and Michael, O. (2013) Factors Influencing Entrepreneurial Intentions among Graduates of Nigerian Tertiary Institutions. International Journal of Business and Management Invention, 2, 36-44.

[5] Yusop, Z.M., Misnan, N. and Abdul Razak, N. (2017) Predicting Entrepreneurial Intentions of Private College Students by Applying the Theory of Planned Behavior. Being a Paper Presented at Global Conference on Business and Economics Research, Universiti Putra Malaysia, Malaysia.

[6] Neneh, B.N. (2014) An Assessment of Entrepreneurial Intention among University Students in Cameroon. Mediterranean Journal of Social Sciences, 5, 544-552.

https://doi.org/10.5901/mjss.2014.v5n20p542

[7] Garba, S.A., Kabir, S. and Nalado, A.M. (2014) An Assessment of Students' Entrepreneurial Intentions in Tertiary Institution: A Case of Kano State Polytechnic, Nigeria. International Journal of Asian Social Science, 4, 434-443.

[8] Caliendo, M., Fossen, F. and Kritiko, A.S. (2011) Personality Characteristics and the Decision to Become and Stay Self-Employed. SOEP Papers on Multidisciplinary Panel Data Research, No. 369. Deutsches Institutfür Wirtschaftsforschung, Berlin. http://hdl.handle.net/10419/150914 https://doi.org/10.2139/ssrn.1846400

[9] Akhuemonkhan, A., Raimi, L. and Sofoluwe, A.O. (2013) Entrepreneurship Education and Employment Stimulation in Nigeria. Journal of Studies in Social Sciences, 3, 55-79.

[10] Volkman, C., Wilson, K., Marlotti, S. and Rabuzzi, D. (2009) Educating the Next Wave of Entrepreneurs-Unlocking Entrepreneurial Capabilities to Meet the Global Challenges of the 21st Century. A Report of the Global Education.

https://doi.org/10.2139/ssrn.1396704

[11] OECD (2015) Entrepreneurial Learning Environments and a Changed Role for Teachers. Thematic Paper on Entrepreneurial Schools Part 2.

[12] Arogundade, B.B. (2011) Entrepreneurship Education: An Imperative for Sustainable Development in Nigeria. Journal of Emerging Trends in Educational Research and Policy Studies, 2, 26-29.

[13] Baba, G.K. (2013) The challenges of Entrepreneurship Development in Nigeria and Way Forward. Journal of Business and Organizational Development, 5, 54-64.

[14] Aja-Korie, U. and Adali, O. (2013) Achieving Youth Empowerment through Repositioning Entrepreneurial Education in Nigerian Universities: Problems and Prospects. European Journal of Business and Social Sciences, 1, 59-67.

[15] Adebayo, O. and Kolawale, J.A. (2013) The Historical Background of Entrepreneurial Development in Nigeria: Its Gains, Shortcomings and Needful. Journal of Emerging Trends in Economics and Management Sciences, 4, 493-500.

[16] Ayodele, K.O. (2017) Perceptions of Students on Entrepreneurship Education and 
Entrepreneurial Intentions in Selected Nigerian Universities. Being Thesis Submitted to the Department of Business Management, College of Business and Social Sciences, Covenant University, Ota, Ogun State, Nigeria.

[17] Ismail, M.Z. and Ahmad, S.Z. (2013) Entrepreneurship Education: An Insight from Malaysian Polytechnics. Journal of Chinese Entrepreneurship, 5, 144-160. https://doi.org/10.1108/JCE-02-2013-0003

[18] Ojeifo, A. (2012) Entrepreneurship Education in Nigeria. Journal of Education and Practice, 3, 78-82.

[19] Lee, S.M., Chang, D. and Lim, S.B. (2005) Impact of Entrepreneurship Education: A Comparative Study of the US and Korea. The International Entrepreneurship and Management Journal, 1, 27-43. https://doi.org/10.1007/s11365-005-6674-2

[20] Valerio, A., Parton, B. and Robb, A. (2014) Entrepreneurship Education and Training programs around the World: Dimensions for Success. World Bank Publications, Washington DC. https://doi.org/10.1596/978-1-4648-0202-7

[21] Vestergaard, L., Moberg, K. and Jorgensen, C. (2012) Impact of Entrepreneurship Education in Denmark. http://archive.jaye.org/download

[22] Watson, K., Hogarth-Scott, S. and Wilson, N. (1998) Small Business Start-Ups: Success Factors and Support Implications. International Journal of Entrepreneurial Behaviour \& Research, 4, 217-238. https://doi.org/10.1108/13552559810235510

[23] Thompson, E.R. (2009) Individual Entrepreneurial Intent: Construct Clarification and Development of an Internationally Reliable Metric. Journal of Entrepreneurship Theory and Practice, 33, 669-694. https://doi.org/10.1111/j.1540-6520.2009.00321.x

[24] Delmar, F. and Davidsson, P. (2000). Where Do They Come from? Prevalence and Characteristics of Nascent Entrepreneurs. Entrepreneurship \& Regional Development, 12, 1-23. https://doi.org/10.1080/089856200283063

[25] Oosterbeek, H., Van Praag, M. and Ijsselstein, A. (2010) The Impact of Entrepreneurship Education on Entrepreneurship Skills and Motivation. European Economic Review, 54, 442-454. https://doi.org/10.1016/j.euroecorev.2009.08.002

[26] Ajzen, I. (1991) The Theory of Planned Behavior. Organizational Behavior and Human Decision Processes, 50, 179-211. https://doi.org/10.1016/0749-5978(91)90020-T

[27] Ashley-Cotleur, C., King, S. and Solomon, G. (2009) Parental and Gender Influences on Entrepreneurial Intentions, Motivations and Attitudes. George Washington University, Washington DC.

[28] Kolvereid, L. (1996) Prediction of Employment Status Choice Intentions. Entrepreneurship Theory and Practice, 20, 23-31. https://doi.org/10.1177/104225879602000302

[29] Adeyemo, S.A. (2009) Understanding and Acquisition of Entrepreneurial Skills: A Pedagogical Re-Orientation for Classroom Teacher in Science Education. Journal of Turkish Science Education, 6, 57.

[30] Cho, B. (1998) Study of the Effective Entrepreneurship Education Method and Its Process. Business Education Research, 2, 27-47.

[31] Han, J. and Lee, M. (1998) A study on the Status of Entrepreneurship Education in Korea and Its Direction. Business Education Research, 2, 5-26.

[32] Timmons, J.A. (1999) New Venture Creation: Entrepreneurship for 21st Century. 5th Edition, Irwin-McGraw-Hill, Homewood, IL.

[33] Wilson, F., Kickul, J. and Marlino, D. (2007) Gender, Entrepreneurial Self-Efficacy, 
and Entrepreneurial Career Intentions: Implications for Entrepreneurship Education. Entrepreneurship Theory and Practice, 31, 387-406.

https://doi.org/10.1111/j.1540-6520.2007.00179.x

[34] Souitaris, V., Zerbinati, S. and Al-Laham, A. (2007) Do Entrepreneurship Programmes Raise Entrepreneurial Intention of Science and Engineering Students? The Effect of Learning, Inspiration and Resources. Journal of Business Venturing, 22, 566-591. https://doi.org/10.1016/j.jbusvent.2006.05.002

[35] Turker, D. and Sonmez Selçuk, S. (2009) Which Factors Affect Entrepreneurial Intention of University Students? Journal of European Industrial Training, 33, 142-159. https://doi.org/10.1108/03090590910939049

[36] Lucky, E.O. and Ibrahim, N.A. (2015) Environmental Factors and Entrepreneurial Intention among Nigerian Students in UUM. Journal of Sains Humanika, 5, 87-93.

[37] Saptono, A. and Purwana, D.E.S. (2016) Learning Environment, Self-Efficacy, and Attitude Impact Vocational Students' Entrepreneurial Intention? International Journal of Environmental Research, 2, 50-60.

[38] Bany, M.A. and Johson, L.V. (1975) Educational Social Psychology. Publishing Co., New York.

[39] Simola, V. (2011) Intrinsic or Extrinsic? A Study on Motivational Factors among a Network of Entrepreneurship Mentors: Case Venture Cup Finland. Master's Thesis, Aalto University, Espoo, "Helsinki, Finland.

[40] Shapero, A. and Sokol, L. (1982) Social Dimensions of Entrepreneurship. In: Kent, C.A., Sexton, D.L. and Vesper, K.H., Eds., Encyclopaedia of Entrepreneurship, Prentice Hall, Englewood Cliffs, NJ.

[41] Eijdenberg, E.L. and Masurel, E. (2013) Entrepreneurial Motivation in a Least Developed Country: Push Factors and Pull Factors among MSEs in Uganda. Journal of Enterprising Culture, 21, 19-43. https://doi.org/10.1142/S0218495813500027

[42] DeMartino, R. and Barbato, R. (2003) Differences between Women and Men MBA Entrepreneurs: Exploring Family Flexibility and Wealth Creation as Career Motivators. Journal of Business Venturing, 18, 815-832. https://doi.org/10.1016/S0883-9026(03)00003-X

[43] Kothari, C.R. (2004) Research Methodology, Methods and Techniques. 2nd Edition, New Age International Publishers, New Delhi, India.

\section{Abbreviations and Acronyms}

Entrepreneurial Learning Environment (ELE), Intrinsic Learners' Need (ILN), Entrepreneurial Learning Outcome (ELO), Entrepreneurial Motivation (EM), Entrepreneurship Education Programme (EEP), Bayero University, Kano (BUK), Kano University of Science and Technology (KUST), Yusuf Maitama Sule University, Kano (YUMSUK) 